\title{
Stimulation of uterine activity by administration of prostaglandin F-2 $\alpha$ during parturition in sheep
}

\author{
M. D. Mitchell, A. P. F. Flint and A. C. Turnbull \\ Nuffield Department of Obstetrics \& Gynaecology, John Radcliffe Hospital, \\ Headington, Oxford OX3 9DU, U.K.
}

In sheep, prostaglandin (PG) F-2 $\alpha$ concentrations rise in uterine venous plasma and in myometrium and maternal cotyledons before dexamethasone-induced parturition (Liggins \& Grieves, 1971). As in many other species these high PGF- $2 \alpha$ concentrations are thought to play a role in stimulating uterine contractions (Thorburn, Nicol, Bassett, Shutt \& Cox, 1972). The experimental evidence to date does not support an acute effect of PGF-2 $\alpha$ in the pregnant ewe (Liggins, Grieves, Kendall \& Knox, 1972; Oakes, Mofid, Brinkman \& Assali, 1973; Keirse et al., 1973). However, a positive effect of chronic PGF-2 $\alpha$ administration on uterine contractility has been reported (Liggins, Fairclough, Grieves, Kendall \& Knox, 1973); in this case the myometrial sensitivity to oxytocin was greatly increased after PGF infusion for $12 \mathrm{hr}$ and spontaneous uterine contractions were observed after $24 \mathrm{hr}$ of treatment. This report describes experiments designed to determine whether PGF- $2 \alpha$ can exert an acute effect on uterine activity during parturition in sheep.

Aortic, amniotic, fetal and utero-ovarian venous catheters were established in 5 ewes between Days 128 and 137 of gestation. All animals gave birth to live lambs. Intra-fetal dexamethasone administration was used to induce parturition in 4 of these animals; in such ewes the endocrine changes are similar to those associated with spontaneous parturition at term (Liggins et al., 1972; Thorburn et al., 1972). Dexamethasone was infused at a rate of 1-3 mg/24 hr into the fetal vena cava through a catheter inserted via a tarsal vein. For these 4 animals the mean $( \pm$ S.D.) time from induction to parturition was $41 \pm 9 \mathrm{hr}$. The fifth animal gave birth spontaneously on Day 144 of gestation. The concentrations of progesterone, total unconjugated oestrogens and PGF were measured by radioimmunoassays as previously described (Flint, Anderson, Patten \& Turnbull, 1974; Mitchell, Flint \& Turnbull, 1975). Serial infusions of PGF-2 $\alpha$ were performed via the maternal aorta, with PGF-2 $\alpha$ (THAM salt) being infused at a rate which resulted in uterine venous plasma PGF levels similar to those found previously at term (Table 1).

Table 1. Hormone levels in the utero-ovarian venous plasma of Ewe 1 during and $4 \mathrm{hr}$ after (figures in parentheses) experiment

\begin{tabular}{ccccc}
\hline Exp. & $\begin{array}{c}\text { Time before induced } \\
\text { parturition } \\
(\mathrm{hr})\end{array}$ & $\begin{array}{c}\text { Progesterone } \\
(\mathrm{ng} / \mathrm{ml})\end{array}$ & $\begin{array}{c}\text { Total unconjugated } \\
\text { oestrogens } \\
(\mathrm{pg} / \mathrm{ml})\end{array}$ & $\begin{array}{c}\text { PGF } \\
(\mathrm{ng} / \mathrm{ml})\end{array}$ \\
\hline 1 & 48 & $45 \cdot 8(43 \cdot 0)$ & $<20(20)$ & 34 \\
2 & 28 & $38 \cdot 0(31 \cdot 0)$ & $<20(20)$ & 45 \\
3 & 19 & $25 \cdot 3(15 \cdot 6)$ & $42(120)$ & 35 \\
4 & 9 & $9 \cdot 0(10 \cdot 7)$ & $220(306)$ & 25 \\
5 & 4 & $10 \cdot 7(8 \cdot 3)$ & $306(400)$ & 44 \\
\hline
\end{tabular}

The response to intra-aortic infusion of PGF- $2 \alpha$ was similar in all 4 treated ewes ( 3 induced parturitions and one of natural onset). The results for one of these animals are shown in Plate 1 and Table 1. In the fifth animal the infusion catheter was inserted to a point posterior to the junction of the iliac and uterine arteries: infusion of PGF- $2 \alpha(125 \mu \mathrm{g} / \mathrm{min})$ in this animal and intra-aortic saline infusion in another produced no change in uterine contractility (results not shown). There were no changes in the concentrations of progesterone and total unconjugated oestrogens in uterine venous plasma samples taken during the first infusion in Ewe 1 (Plate 1). The pressure recordings were analysed 
manually in terms of Montevideo units as defined by Caldeyro-Barcia et al. (1957), i.e. the product of intensity (rise in pressure in $\mathrm{mmHg}$ each contraction produces in the amniotic fluid) and frequency (number of contractions/10 min). The results for the total experimental period were averaged for comparison with the total control period. The amplitude of contraction was taken as the distance between peak and base of each contraction. Intrauterine pressure changes in response to PGF-2 $\alpha$ showed a characteristic pattern in all 4 treated animals, an initial hypertonus being followed by increased uterine contractility. Closer to parturition there was an apparent increase in response in all the ewes, the effect being both greater and longer lasting. There was a mean tenfold stimulation of uterine activity during the infusions compared to the relevant control periods $(P<0.005$, one-tailed $t$ test).

The immediate effect of PGF-2 $\alpha$ on uterine activity may have been missed by previous investigators because too low a dose was given. From this study it appears that, apart from an indirect effect on the ovine myometrium by a lowering of the oxytocic threshold, PGF- $2 \alpha$ can also exert an acute effect on uterine contractility. This is consistent with the idea that the surge of PGF-2 $\alpha$ at term is the final impetus for fetal expulsion in the sheep.

We are grateful to Dr B. J. Furr, I.C.I. Pharmaceuticals Division, Alderley Park, Cheshire, Dr K. J. Thrower, Upjohn Ltd, Crawley, Sussex and Dr K. T. Kirton, Upjohn Ltd, Kalamazoo, Michigan, U.S.A. for gifts of antisera and prostaglandin standards. We also thank Professor G. S. Dawes for animal facilities, and the M.R.C. for a Studentship to M. D. M. and Grant No. G971/ $809 / \mathrm{C}$.

\section{References}

Caldeyro-Barcia, R., Sica-Blanco, Y., Poseiro, J.J., Gonzalez-Panizza, V., Mendez-Bauer, C., Fielitz, C., Alvarez, H., Pose, S.V. \& Hendricks, C.H. (1957) A quantitative study of the action of synthetic oxytocin on the pregnant human uterus. J. Pharmac. exp. Ther. 121, 18-31.

Flint, A.P.F., Anderson, A.B.M., Patten, P.T. \& Turnbull, A.C. (1974) Control of utero-ovarian venous prostaglandin $F$ during labour in the sheep: acute effects of vaginal and cervical stimulation. J. Endocr. 63, 67-86.

Keirse, M.J.N.C., Patten, P.T., Anderson, A.B.M., Turnbull, A.C., Johns, A., Wooster, M.J. \& Pickles, V.R. (1973) Pregnant sheep myometrium responds to prostaglandins in vitro but not in vivo. Int. Res. Commun. Syst. April 1973.

Liggins, G.C. \& Grieves, S.A. (1971) Possible role for prostaglandin F-2 $\alpha$ in parturition in sheep. Nature, Lond. 232, 629-631.

Liggins, G.C., Grieves, S.A., Kendall, J.Z. \& KNOX,
B.S. (1972) The physiological roles of progesterone, oestradiol-17 $\beta$ and prostaglandin $F-2 \alpha$ in the control of ovine parturition. J. Reprod. Fert., Suppl. 16, 85103.

Liggins, G.C., Falrclough, R.J., Grieves, S.A., Kendall, J.Z. \& KNOX, B.S. (1973) The mechanism of initiation of parturition in the ewe. Recent Prog. Horm. Res. 29, 111-159.

Mitchell, M.D., Flint, A.P.F. \& Turnbull, A.C. (1975) Stimulation by oxytocin of prostaglandin $F$ levels in uterine venous effluent in pregnant and puerperal sheep. Prostaglandins 9, 47-56.

OAKes, G., Mofid, M., Brinkman, C.R. \& Assali, N.S. (1973) Insensitivity of the sheep to prostaglandins. Proc. Soc. exp. Biol. Med. 142, 194-197.

Thorburn, G.D., Nicol, D.H., BassetT, J.M., ShutT, D.A. \& Cox, R.I. (1972) Parturition in the goat and sheep: changes in corticosteroids, progesterone, oestrogens and prostaglandin F. J. Reprod. Fert., Suppl. 16, 61-84.

Received 23 February 1976 
PLATE 1

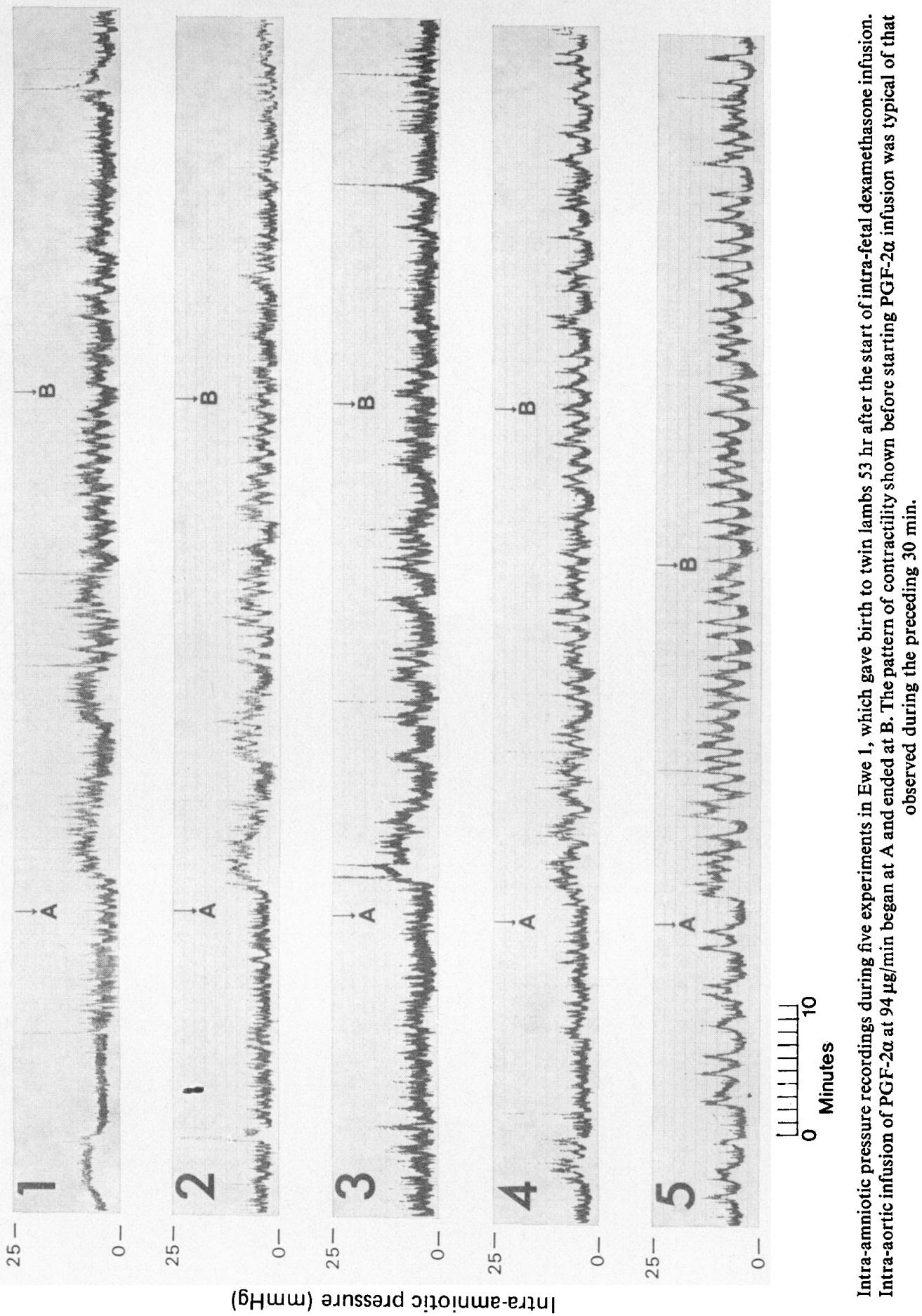

